REVISTA DE SOCIOLOGÍA

$\mathrm{N}^{\mathrm{o}} 17-2003$

Facultad de Ciencias Sociales - Universidad de Chile

(P. 48- 78)

\title{
UN DESAFÍO DEL PENSAMIENTO LATINOAMERICANO ANTE LA TRANSFORMACIÓN RECIENTE
}

\author{
Carlos Ruiz Encina*
}

América Latina tiene fama de arrastrar un hilo histórico lleno de turbulencias y sobresaltos. Extendida es su reputación de recurrentes levantamientos políticos que marcan una agitada existencia desde la conquista española y lusitana, y aún más desde las contiendas independentistas, hasta nuestros días. Sin embargo, al contrario de lo que indica el corolario que livianamente se desprende de esa difundida imagen, que lleva a fraccionar excesivamente su curso bajo reiterados cambios, uno de los rasgos fundamentales de gran parte de la historia de América Latina es, más bien, su porfiada invariabilidad.

Vale la pena tomar con más cautela la extrapolación de tales estereotipos, incluso invertir el planteo, indagando si no es acaso la gran estabilidad de sus estructuras de poder -insólita si se compara con buena parte del curso europeo contemporáneo- la que a fin de cuentas, y a pesar de tanto innegable sobresalto, acaba las más de las veces impidiendo cambios de mayor hondura. Firmemente afincada en la región, existe una estructura tradicional de instituciones y un entramado no menos importante de formas no institucionales de poder, ambas mucho más elásticas, adaptativas y supervivientes de lo que habitualmente supone el recuento abocado a relevar procesos de cambio y modernización que siguen una lógica similar a la europea. De ellas se derivan preceptos jerárquicos, actitudes y valores culturales de largas raíces que inciden en modo gravitante en los procesos políticos latinoamericanos contemporáneos. Estas estructuras y formas de poder han sobrevivido durante siglos de orden colonial, movimientos de independencia, reiteradas invasiones externas y turbulentas revoluciones internas, así como a una harto más abundante cuota de revueltas palaciegas y crisis políticas menores. En el siglo recién pasado estas estructuras y modos del poder no sólo resistieron con éxito el impacto de las enormes transformaciones tecnológicas y la llegada de la industrialización, sino que, a juzgar por el sello marcadamente conservador de las transformaciones sociales y políticas que se imponen en sus últimas décadas, no resulta descabellado pensar que éstas parecen haberse fortalecido, ocupando lugares de primera línea en la marcha con que América Latina atraviesa el umbral del nuevo milenio.

\footnotetext{
* Profesor de Historia Social de América Latina, Departamento de Sociología, Universidad de Chile.
} 


\section{La latencia de viejos problemas}

El siglo XX latinoamericano atesora el arranque de la industrialización, cobija también el ingreso al poder de las clases medias así como su fracaso en el impulso de los cambios requeridos para viabilizar el salto hacia un añorado desarrollo sostenido. Por décadas se esperó que las clases medias criollas fuesen capaces de producir los cambios culturales e institucionales indispensables para el avance de la industria. Las crecientes expectativas de las masas populares, sobre todo urbanas, el impacto cultural de la tecnología moderna, el auge de la industria, eran factores que, unidos a la decidida acción política -guiada por intereses propios, por cierto- de una clase media de progresista y modernizadora, reformadora y antiaristocrática, habían de bastar para resolver el dilema del desarrollo.

Pero el problema no se resolvió. Las clases medias estuvieron en el poder por varias décadas, participaron del avance industrial, sin embargo, aunque con matices propios de las diferencias regionales, finalmente fueron responsables de la perduración de la estructura tradicional en los principales países de América Latina. Llegaron a eso precisamente por proteger sus intereses y horizontes futuros. Lejos de barrer definitivamente con los cimientos del Antiguo Régimen criollo, su inseguridad ayudó a la sobrevivencia, adaptada a las nuevas condiciones, de importantes fuerzas y rasgos del viejo orden. En vez de ello, se esforzaron por vincularse a la aristocracia. Pues sucede que, el acceso de las clases medias al poder político en América Latina llega sin que éstas antes se hubiesen convertido en económicamente poderosas, contrariando así la ruta clásica del ascenso social según la cual un grupo primero alcanza el poderío económico, luego intenta la representación política y, finalmente, aspira al más esquivo prestigio social. En América Latina, el ingreso de las clases medias al poder y su liderazgo político no tuvo que ver con el auge industrial ni con su enriquecimiento. Forjada bajo el auge primario-exportador decimonónico y moldeada en la ambigua modernidad urbana preindustrial ligada a él, catapultada al primer plano por el desplome de la hegemonía oligárquica y su capacidad de control social, y más tarde por el golpe de gracia que, para el viejo modelo, traían los vientos foráneos de la Gran Depresión y su impulso a una no deliberada industrialización, entonces las clases medias criollas ingresan al poder político sobre todo por la fuerza del voto de las masas urbanas, que les apoyan porque representan la única alternativa reformista frente a los grupos tradicionales.

Por cierto, ante la estructura social del privilegio y de poder tradicionales se plantearon trocarla por una más igualitaria en la que, por lo menos, sus partidarios urbanos encontraran acomodo. Sin embargo, las décadas de crecimiento industrial espontáneo no dieron lugar a una cultura industrial capaz de erigirse en una alternativa al acervo cultural tradicional de la clase alta. Dicho en otros términos, no dió lugar a una ética del trabajo, como la que Weber distinguía para la experiencia renana, o a una nueva hegemonía cultural. En Europa, especialmente en la referencial experiencia inglesa, el auge de la industria trae consigo una honda renovación cultural. La burguesía industrial lejos de imitar los modales y actitudes de la vieja aristocracia, como en cambio ocurre en América Latina, imponía su propio estilo de vida a toda la nación. Empero, si ello no sucede en América Latina, no es por la pereza de unas lumpenburguesías nacidas con la conquista, resignadas a un secundón rol satelital en su relación dependiente con las metrópolis capitalistas de turno en la economía mundial. Se debe, más bien, a la inexistencia de unas genuinas burguesías schumpeterianas o simplemente de unas bourgeoisies conquerantes en América Latina, a la debilidad 
endémica de las burguesías históricamente existentes, provenientes apenas del siglo XIX, incapaces de desafiar radical y frontalmente a las viejas oligarquías, situación que, aunque ascendentes, aqueja también a las clases medias criollas del siglo XX. Si el expansivo desarrollo capitalista de América Latina en la segunda mitad del siglo XIX no fue lidereado por burguesías, no menos paradojal resulta que la industrialización latinoamericana del siglo siguiente no fuese producto de las actividades de una burguesía industrial en ascenso.

Fuera de su singular capacidad de supervivencia las oligarquías de los diversos países latinoamericanos tienen poco en común. Provienen de diferentes regiones de la península ibérica, a veces apenas integradas culturalmente -como las Españas del tiempo imperial- y hasta se forman en distintas épocas entre el siglo XVI y principios del siglo XIX. Empero, todas resultan largamente aceptadas como aristocracias en sus diversos contextos sociales. Por generaciones el mismo puñado de familias permanece cerca de las fuentes del poder político y social, goza de gran riqueza y conserva un monopolio indiscutido del prestigio social. De hecho, a falta de una jerarquía alternativa de valores culturales y símbolos de prestigio, la única posibilidad de alcanzar cierto prestigio social consiste en asociarse con la aristocracia tradicional, casando los hijos con los de aquella, enviándolos a sus exclusivas escuelas, comprando tierras y caballos, aprendiendo los empingorotados juegos y deportes de esa clase alta, entrando en la nómina de los clubes aristocráticos, imitando sus formas de hablar. Las clases medias urbanas, al igual que las burguesías criollas, han hecho esto en forma sistemática. Y las clases altas no lo han visto con disgusto; más bien, a cambio de los apoyos políticos y financieros que han necesitado para pervivir, lo han alentado.

De manera que no es poco lo que sobre el presente puede alumbrar la discusión histórica. Si nos situamos en el debate de esos años sesenta y el inicio de la década siguiente, uno de los cursos más prolíficos en la construcción de conocimiento sobre la realidad latinoamericana, como punto para retomar un esfuerzo por pensar la región, nos encontramos con el dilema que ésta es vista casi exclusivamente como una parte del mundo muy dependiente de los ritmos y necesidades de las naciones más poderosas, condición que arroja una escuálida, sino nula, capacidad de afirmarse y procurarse estabilidad interna. Sin dejar de haber una cuota de verdad en ello, su extrapolación desmedida, que ha pretendido ver allí el origen de todos los problemas, redujo las cosas a una lectura que no repara en la singular estabilidad de las jerarquías operantes, comúnmente ligadas a un grupo de estructuras familísticas, ni en la pasmosa inmovilidad de las clases y grupos por ellas determinadas, adaptadas con gran elasticidad a los diversos escenarios históricos. Lo que a fin de cuentas, a pesar de las recurrentes turbulencias, ha hecho que, en términos de las estructuras sociales y de poder, los cambios resulten menos abruptos y esenciales, más graduales y limitados de lo que parece sugerir un curso histórico con tanto sobresalto, dado que las viejas oligarquías, cuando no logran frenar las improntas de cambio, al menos han conseguido encauzar en una arrolladora mayoría de ocasiones el rumbo que perfilaba su ímpetu original.

Vista América Latina bajo el prisma de su sujeción a los centros capitalistas mundiales, y derivando de ello una supuesta incapacidad estructural para afirmarse internamente, resulta que comparativamente es poca la atención que se ha puesto sobre la formación y el desarrollo de las estructuras de poder y de dominio que tienen lugar en sus propias entrañas. Mucho más ocupada -en algún tiempo casi absorta- en ver cómo y cuánto nos expolian desde fuera, la mirada repara tanto menos en qué ocurre con lo que queda aquí, el tipo de 
orden que, a pesar de todo, acaba produciéndose por estos lares. Y es que, vista desde este otro ángulo, la historia aparece en una forma sorprendentemente más contínua e inmutable.

Empero, ¿cómo es que tanta inestabilidad no desemboca en cambios más radicales? La respuesta remite a urgar en el proceso de formación histórica de las estructuras de poder en América Latina. Por cierto, inestabilidad no implica necesariamente ruptura. Vista desde la perspectiva del orden social y sus estructuras sociales, el devenir latinoamericano muestra una continuidad pasmosa, lo que pareciera contradecirse con su arraigada inestabilidad política. Es una crónica inestabilidad dentro de lo mismo. La escasez de rupturas sociales y culturales significativas no implica necesariamente estabilidad y calma. La alta dosis de agitación presente en la historia de la región se ubica mayormente en el terreno de pugnas que se resuelven entre facciones de los grupos dominantes, en pos del manejo de un mismo sistema de poder. Rara vez se trata del ascenso genuino de nuevos grupos sociales, casos que por lo regular desembocan -luego de las mediciones de fuerza de rigor- en pactos de integración de esos nuevos sectores a un orden reestructurado a partir de su cohabitación en el pináculo del poder con las fuerzas tradicionales, dando lugar a una estructura de poder más compleja y heterogénea en la que la vieja oligarquía se ha acomodado para sobrevivir.

A pesar de la continua mutación formal de los órdenes políticos e institucionales a través de la historia, cuestiones como la superación del atraso o el cambio social -véanse o no ligadas entre sí- se estrellan porfiadamente contra los mismos muros, hoy como ayer, revestidos de nuevas formas, pero sostenidos por los mismos apellidos. Son, en buena parte, los mismos que los sostienen allá en las postrimerías del siglo XIX, ante la presión de los locos años veinte de la pasada centuria, en el lapso que corre entre los treinta y los cincuenta, harto más inquieto de lo que se suele recordar, o ante los reconocidamente revueltos años sesenta y setenta del siglo que recién se fue. Hoy, aunque bajo nuevas formas y con algunos cambios a cuestas, puede distinguirse un hilo de continuidad en la historia del poder, de sus forjadores y beneficiarios: las clases dominantes criollas. Precisamente, la desconcertante continuidad en el poder por parte de ciertos grupos sociales, ya sea solos o en alianzas, ha llevado a que los cambios sociales, cuando no logran evitarse, procedan de modo trasvestido, sin que se distingan -salvo excepciones que confirman la regla- verdaderos procesos de revolución social, expresados en genuinas rupturas con el orden social y cultural antecedente. Dentro de amplios períodos se registran, producto de ello, valores, patrones de comportamiento y actitudes de una extraordinaria continuidad en América Latina. Los patrones socioculturales ligados a la hacienda, la mentalidad asociada a la forja de fortuna a partir de la exportación de productos primarios o una tradición de derecho privado a los cargos públicos, son algunos ejemplos de elementos que cobran una influencia decisiva en la formación de la cultura política $\mathrm{y}$, con ello, en los procesos políticos contemporáneos.

En parte importante, los procesos políticos actuales tienen que ver con la naturaleza específica que asumen esas clases dominantes en América Latina. Y dicha naturaleza no es, de ningún modo, cosa de reciente formación. De modo que, en este sentido, es preciso mirar hacia atrás para entender el presente, por más que un discurso alusivo a una supuesta condición posmoderna, a guisa de importada moda de ocasión, pretenda desconocer la construcción histórica de nuestra actualidad. Frente a su discurso deshistorizante, el remedio más efectivo es problematizar históricamente el presente. 


\section{Recuperación crítica de la lectura acumulada}

En tal sentido, resulta inevitable dialogar con el debate latinoamericano de los años sesenta y setenta del siglo recién pasado, como ya se dijo, una de las más fructíferas improntas de construcción de conocimiento sobre la región. Al ser el punto más adecuado para recuperar una discusión sistemática -las elaboraciones posteriores, sin desmerecerlas, no se enmarcan en un curso tan extendido y colectivo- es preciso encarar ciertos simplismos que ésta arroja, muy difundidos en el modo de situar la problemática latinoamericana. Separar paja de trigo, asumir que las rigideces y los reduccionismos existieron, como también ideas sugerentes pero olvidadas, es una tarea necesaria para recuperar un hilo de reflexión al que hoy es posible incorporar nuevos conocimientos y campos de observación.

Tal cual se manejó en forma predominante, la idea de la dependencia estructural hace aparecer a los grupos de poder locales como meros y mudos eslabones de una larga cadena de sucesivas metrópolis y satélites. Junto con ello, el constante sobresalto de la historia latinoamericana aparece, entonces, como simple efecto de los cambios en la dinámica económica de los centros metropolitanos: la tendencia es a ver un origen externo en los procesos sociales locales. Eso hizo ignorar la asombrosa capacidad de los grupos de poder criollos para perdurar e impedir cambios mayores en el orden social. Pero tal rigidez analítica, dogmática muchas veces, capaz de limitar el alcance de empresas intelectuales tan prometedoras como aquella, no surgen del vacío: tienen su propia historia. El sesgo economicista es una de las taras que van a limitar este empeño por aproximarse a la especificidad de la condición latinoamericana.

Casi premonitoriamente, unos años antes Medina Echavarría advertía que el tema del atraso ya lo cruzaba prácticamente todo, y que lo hacía bajo el formato de visiones de índole económica ${ }^{44}$. La avalancha de conocimientos que producían las formas de indagación de la ciencia económica, de moda y en plena expansión entonces, invadía y reordenaba otros campos de la construcción del conocimiento, dejando casi atónitas a las demás disciplinas del pensamiento social. Por si fuera poco, eso se cruzaba con otra impronta. Iniciado casi con el siglo XX, el largo curso de debilitamiento del ethos sociocultural que acompañó al orden político y económico centrado en la hacienda, urgía la búsqueda de una alternativa que lo reemplazara. Estimulaba así un esfuerzo por dilucidar a una nueva clase dirigente que tomara el timón de la gran nave de las naciones latinoamericanas.

El centro de las más variopintas disquisiciones intelectuales pasaba a ser el problema del atraso. Tal era el tenor de la prise de conscience que marcaba una bullente reanimación del pensamiento latinoamericano. Y ese fue, también, el terreno propicio para que la izquierda tradicional y los nuevos movimientos revolucionarios latinoamericanos, entonces en ascenso, se inclinaran, entre las diversas corrientes que emanaban del marxismo, por los enfoques estructuralistas que resonaban desde París, abriendo bajo tal égida un sesgo que, junto al economicismo anterior, cobraría una pesada influencia sobre la sugestiva empresa

\footnotetext{
${ }^{44}$ Medina Echeverría, José, Consideraciones sociológicas sobre el desarrollo económico, Ed. Solar-
} Hachette, Buenos Aires, 1964. 
de desnudar la naturaleza dependiente de nuestro atraso. Así pues, aunque la elaboración que luego se aglutina alrededor de la llamada teoría de la dependencia no se circunscriba a un ámbito particular de la realidad ni a una disciplina específica, tales marcas perdurarán. Pese a que se hablará de dependencia económica, política o cultural y a que ingresarán al debate lo mismo economistas, sociólogos, politólogos, historiadores que personas provenientes del quehacer político concreto, un estructuralismo de tipo economicista tenderá a predominar por sobre otros enfoques, lo que no quita que, como ha sido característico de la cultura latinoamericana, en dicho debate, como ocurre en general con las discusiones acerca de sus opciones de futuro, se constituya éste en un tema de reflexión casi obligada para todos aquellos que en distintos campos ejercen una labor intelectual.

Por cierto, el tema del atraso ha estado siempre presente en la reflexión latinoamericana, no sólo en su vertiente económica, debatiéndose ya sea sobre su origen o acerca de las vías para su superación. El esfuerzo por configurar un pensamiento original acerca de la región viene desde más atrás, con su estela de logros y accidentes. Mariátegui y Haya de la Torre son genuinos pioneros en el empeño por superar los enfoques eurocentristas sobre América Latina y en la comprensión de la especificidad del capitalismo en la región. Aún cuando representan una impronta interrumpida, tanto por la represión desatada sobre la izquierda criolla en los años veinte y treinta del siglo pasado, como por la influencia doctrinaria de una III Internacional que eludía el estudio particular de la realidad latinoamericana al englobarla bajo lo que su IV Pleno definiera como la China del Lejano Occidente, ésta reaparece en los años cuarenta y los inicios de los cincuenta a través de la recuperación de algunas temáticas con Jobet y Segal en Chile, Prado Junior, Buarque de Holanda y Sodré en Brasil, Frondizi y Bagú en Argentina. Este último, pionero en la formulación del problema de la dependencia. Ya entrados los años cincuenta y en los inicios de los sesenta, con el avance de la institucionalización de las ciencias sociales aparece el estudio sistemático de la realidad latinoamericana con autores como Medina Echavarría y Germani, que abordan la particularidad histórica de la estructura social latinoamericana, la influencia del sistema oligárquico de haciendas o discuten los rasgos de la modernización en América Latina.

Pero no es sino con la CEPAL que llega la primera concepción estructurada sobre la región. El Informe Económico de América Latina de 1949, marca el inicio de una teorización sistemática y extendida sobre la situación latinoamericana, dando lugar a una influyente corriente de pensamiento, en un hilo de reflexión en el que emerge con fuerza la vinculación de los procesos internos latinoamericanos con los ciclos del capitalismo mundial a través de enfoques económicos principalmente.

La CEPAL nacía en medio del intento por difundir la teoría del desarrollo. Como se sabe, en dicha formulación el desarrollo aparecía como un proceso continuo: todos los países aparecían situados en distintas fases de ese continuum, que comprendía así a toda la economía mundial. Su formulación clásica comprendía una teoría del despegue que aludía al momento que separa la fase pre y post desarrollo industrial. Lo que después se llamará subdesarrollo es aquí una etapa previa al momento del despegue, una etapa hacia el desarrollo en la que se crean las condiciones para el salto. En tal esquema, todas las economías del sistema mundial tienen la posibilidad de acceder al desarrollo económico pleno. Pero la CEPAL surge ligada a la realidad interna y, como tal, inclusive, va a reflejar de cierta manera las pugnas entre los grupos de poder latinoamericanos. Es por eso que 
introduce nuevos elementos en la teoría del desarrollo, tensionándola con su crítica al sistema de relaciones entre las economías latinoamericanas y las de los centros capitalistas.

La irrupción del pensamiento cepalino inaugura así un proceso de teorización sobre el subdesarrollo de América Latina completamente distinto a las lecturas de la economía convencional sobre el tema. Una de sus grandes contribuciones va a ser su crítica a la teoría clásica del comercio internacional y su principio de las ventajas comparativas, según el cual cada país se especializa en un tipo de producción en que tiene mejores condiciones de competencia, y cuyos resultados en un mercado mundial así configurado favorece a todos, en tanto cada uno desarrolla el máximo de productividad. La CEPAL demostrará que eso no es así, que esas relaciones comerciales están marcadas por un deterioro de los términos del intercambio en perjuicio de los países exportadores de bienes primarios, y que esa es una tendencia permanente. Ello propicia transferencias de ingreso que se realizan por la vía de los precios desde los países subdesarrollados a los desarrollados, lo que significa una descapitalización constante de éstos a favor de los desarrollados, por lo que concluye que el desarrollo de los países industrializados está estrechamente ligado al origen del subdesarrollo de los países primario-exportadores.

Para la CEPAL la idea de desarrollo económico no se asume restringida a una economía aislada, sino en el contexto de un sistema centro-periferia de naturaleza desigual. Centros y periferia surgen históricamente como resultado de la forma en que el progreso técnico se propaga en la economía mundial, originando una diferencia estructural sobre la que se basa la división internacional del trabajo. Vista la desigualdad económica como un hecho inherente a este sistema bipolar, la CEPAL asume que en su evolución la distancia entre los polos crece, producto del deterioro de los términos del intercambio, tendencia que opera a largo plazo determinada por el carácter de los productos que se intercambian (bienes primarios por manufacturas). Se trata del deterioro del poder de compra de los productos periféricos. La tendencia a la desigualdad estructural del sistema es inherente entonces a su propia dinámica. Centros y periferia forman un sistema único, de naturaleza polar, constituido estructuralmente. En fin, un verdadero detonante intelectual que se activaba en medio de un tiempo de esperanzas latinoamericanas.

Pero con esa sugerente elaboración viene también su exageración, y con ello sus limitaciones. Dado su énfasis en la determinación que la marcha del capitalismo desarrollado ejerce sobre el curso latinoamericano, la CEPAL apreciará el proceso de industrialización criollo como espontáneo, en el sentido no deliberado, por estar determinado por los cambios en la economía mundial: llegada ésta a cierto grado de desarrollo, la industrialización resulta la forma necesaria y espontánea de desarrollo periférico. La sustitución de importaciones aparece como la forma obligada de industrialización en la periferia.

No obstante, la CEPAL postula la posibilidad del desarrollo para las economías atrasadas a condición de que se corrijan los desequilibrios del comercio internacional. Para ello fija el imperativo de la industrialización, como medio para acceder al desarrollo y para solucionar los problemas sociales. No plantea reformas que alteren las estructuras heredadas de la economía primario-exportadora, ni una política distributiva que implique la elevación deliberada de los salarios. La propia industrialización y el crecimiento han de resolver los 
problemas sociales y corregir las deformaciones habidas. De ahí el rótulo de desarrollismo sobre la doctrina cepalina, pues es el mismo desarrollo económico el que resuelve los problemas sociales y estructurales de América Latina.

Estas ideas alcanzan gran gravitación en los años cincuenta, incluso dan base a políticas de Estado en varios países. Pero ya en la década siguiente aparecen los problemas y llega a su fin la etapa fácil de la sustitución de importaciones. El estancamiento y los conflictos sociales son agudos, incluso al interior de las propias alianzas sociales en el poder. Los conflictos dentro de los bloques dominantes se acentúan, y también los de éstos con las masas. Junto al ascenso de las masas campesinas y urbanas crece la radicalización política. La CEPAL pasa del desarrollismo inicial a plantear reformas estructurales y luego a caracterizar el estancamiento, cuando ya se inicia la oleada de golpes militares.

En definitiva, el pensamiento cepalino asume un carácter estructuralista a partir de su concepción centro-periferia, y esa será su mayor marca sobre la discusión latinoamericana. Allí se determina la diferenciación estructural entre el aparato productivo de centros y periferia, base de la división internacional del trabajo, y el atraso se explica por las condiciones estructurales en que actúa el aparato productivo periférico. En su carácter estructuralista radica la originalidad de su pensamiento y también su principal limitación: al centrarse en la esfera de la producción se relega el análisis de las relaciones sociales ligadas a ella. Por eso, la CEPAL asume los cambios que ocurren no como resultado de las relaciones entre las clases y grupos sociales, sino como una anomalía, proponiendo ajustar esta realidad a patrones ideales. Al final, si bien el pensamiento cepalino altera muchos de los supuestos con que la economía convencional pretendía explicar el fenómeno del subdesarrollo, no logra superar esos marcos.

Claro que las fuentes de las rigideces que limitan aquella prometedora empresa intelectual no remiten a una trama exclusivamente latinoamericana. El que aquél se convirtiera en un tiempo en que el pensamiento gustara de presentar sus conjeturas como predicciones y sus convicciones como teoremas, tiene que ver, además, con los debates ocurridos en el seno del marxismo europeo, de fuerte influencia sobre la discusión local; sobre todo el que ocurre en Francia que, a diferencia de otras corrientes, pese a su enfoque deshistorizante aparece más vinculado a la lucha política y en particular a la que tenía lugar en el tercer mundo. Aquél fue un tiempo en el que occidente se vira hacia el Tercer Mundo. Le prodiga gran atención en la creencia de que asumía el relevo del ansia emancipadora de una Europa ya cansada de batallar. Aquél fantasma que recorre Europa, anunciado poco más de cien años antes, parecía haber desertado del viejo continente y deambular ahora por los Andes.

En un París que iba hacia la convulsión, un anónimo Louis Althusser pronunciaba el luego famoso seminario estratégico de 1964-65, más conocido como Lire le Capital. Irrumpía como un duro de la ideología, desafiando el relajamiento vigente. Como hecho a la medida del agitado tiempo que se fragua, Althusser parecía sacudir la abulia política e intelectual. Es una irrupción que, en apariencia, viene a terminar con la despolitización y el desgano que carga la producción marxista prácticamente desde la derrota del movimiento obrero europeo de los años veinte, con la apatía arrastrada desde la frustración de las expectativas revolucionarias posteriores al triunfo bolchevique, con un nunca declarado cuestionamiento a la elaboración política de la llamada tradición clásica que, después de Marx y Engels, 
engrosan figuras como Kautsky, Plejanov, Lenin, Luxemburgo, Hilferding, Trotsky, Bauer, Preobrazhensky o Bujarin, todas ellas directamente ligadas a la lucha política, donde el sentido de su labor intelectual, aún cuando con diferentes y hasta opuestas concepciones, aparece nítidamente centrado en los problemas de la lucha política y sus formas de organización. A diferencia de las generaciones posteriores, en aquella tradición tratábase de activistas políticos que asumían como parte de ello la tarea intelectual: la construcción de una teoría política para la cual los fundadores de esta corriente de pensamiento habían dejado apenas algunos rudimentos. En cambio las generaciones siguientes, hijas de las derrotas de las luchas obreras y populares que siguen al triunfo bolchevique, llevarán un camino diferente. Vastos sectores se desentienden de la senda precedente y en la III Internacional se impone el control estalinista, con lo que se apaga la teoría política marxista. El marxismo sigue un rumbo muy distinto al de la tradición clásica.

Exceptuando a Gramsci, las nuevas figuras, como Lukács, Korsch, Benjamin, Horkheimer, Della Volpe, Marcuse, Lefebvre, Adorno, Sartre, Merleau-Ponty, De Beauvoir, Goldmann, el propio Althusser, Colletti, Fromm, Reich, tendrán como rasgo más relevante el divorcio entre ese marxismo y la práctica política. Aquél sello distintivo de la tradición clásica se va a romper cada vez más en el medio siglo que va de 1918 a 1968. La instalación en los años treinta de un centro académico de investigación marxista, la célebre Escuela de Franckfort, marca un hito en este viraje. El escepticismo sobre las posibilidades de la lucha política va unido a un marxismo ahora abocado a las contribuciones filosóficas, literarias y culturales, estéticas, antropológicas y psicológicas. Es el marxismo del fracaso de la revolución socialista fuera de Rusia y de su corrupción dentro de ella. El pensamiento marxista no aborda temas como la democracia representativa y los cambios que produce el rápido avance de la economía capitalista mundial en esas décadas. Lo mismo ocurre con el análisis político del Estado después de Gramsci; la discusión estratégica se anula casi por completo.

En suma es un curso en el que marxismo y revolución no siempre marchan de la mano sino, más bien, mutuamente distanciados. La producción de toda esa pléyade de marxistas difícilmente puede considerarse como una actividad intelectual abocada a la forja de una estrategia de poder anticapitalista para sus condiciones históricas, como había sido la tónica dominante en la tradición clásica. Al reseñar este giro de la producción marxista no se busca establecer un rechazo indiscriminado sobre dichas elaboraciones, sino constatar tal tendencia histórica, contraria a los más difundidos estereotipos esgrimidos tanto en su defensa como para denostarla, puesto que será precisamente tal derrotero lo que, en su momento, parecerá sacudir la irrupción althusseriana en aras de devolver las cosas a su viejo cauce. Y tal supuesto samarrón llega desde una vertiente estructuralista que, siguiendo trazos de Lévi-Strauss, avanza raudamente dentro del marxismo, no sólo dilatando el rumbo anterior sino que imprimiéndole además un giro deshistorizante. En 1962 Lévi-Strauss lanzaba El pensamiento salvaje en contra de Sartre y su Crítica de la razón dialéctica. No sólo contenía aquél, como se sabe, una antropología alternativa, sino que además remataba en un ataque directo al historicismo de Sartre. El fin último de las ciencias humanas no es constituir al hombre, sino disolverlo, concluía Lévi-Strauss, proporcionando con ello la consigna de la década. Y la respuesta marxista llegaba no como repudio al ataque a la historia, sino como refrendo de la propuesta estructuralista: Althusser la aprueba y la incorpora al marxismo, sumándose a la subasta objetivista que acaba expulsando al sujeto del campo de conocimiento, al reificar como objeto de ello a la estructura. 
Althusser despierta una lectura excitante e inspira a muchos. Luego, si se añaden los poderosos imanes de atracción del discurso estructuralista se completa una colección de estímulos difícilmente igualable, a los que no escapa una América Latina que aportaba entonces sus propios factores de excitación intelectual. El origen remoto de la insensibilidad althusseriana con los hechos empíricos, anida en la errada equiparación entre la teoría y el conocimiento. Su teoría del conocimiento, cuyos basamentos rayan en impulsos positivistas, disociados de los hechos históricos, es insosteniblemente internista. Y no es que se trate de relativizar las determinaciones que existen en la realidad. A diferencia de su absoluta noción de causalidad estructural, Brecht observó una vez que si el comportamiento humano parece impredecible, no es porque no haya determinaciones, sino porque hay demasiadas; de ahí el reto de comprender y explicar el hecho históricoconcreto como una unidad de lo diverso, como una síntesis de múltiples determinaciones.

Esa influyente impronta irrumpe en un tiempo de búsqueda para el marxismo postestalinista y en un terreno extraestalinista que pudo ser más fructífero. Es mas, la ausencia de un genuino pensamiento político estratégico, que la irrupción althusseriana sólo nubla con su vehemencia, se prolongará. Su enfoque, por valiosas sugerencias que portara, con su determinismo absoluto de la esencia general de la producción y su deshistorizante consideración de los hombres y las clases sociales como soportes involuntarios de ésta, prisioneros de las ilusiones ideológicas de la experiencia inmediata, simplificaba algunos de los más importantes problemas de Marx, en particular el del cambio histórico. Y su influencia tendrá ese efecto sobre la discusión que ganaba espesor acerca de la naturaleza de la condición latinoamericana. Dado que la principal aplicación de los conceptos de Althusser se producía en el campo político, ello redunda en una visión estructuralista de los actores políticos y sociales latinoamericanos que oscurecía su especificidad histórica.

En la discusión local hay un esfuerzo de relectura histórica en el empeño por descifrar el problema de la dependencia. Pero no es menos cierto que la influencia estructuralista, con su marginación de cualquier criterio exterior de la práctica, como el desarrollo histórico, contribuyó a generar una lectura esquemática de la realidad latinoamericana, ignorante de su especificidad. Si el influyente pensamiento cepalino instalaba un economicismo como antecedente, éste se entronca con una izquierda entonces en ascenso cuyos polos más dinámicos se rinden al influjo del estructuralismo francés, combinación que marcará, en sus sugerencias y limitaciones, los resultados de la prometedora empresa de la teoría de la dependencia, cuyos intelectuales provienen principalmente de esa vertiente política. De ahí la importancia de los modos de recepción del pensamiento ultramarino en América Latina: emerge un estructuralismo economicista, determinista, muchas veces dogmático, que no es una réplica pasiva del pensamiento althusseriano. Mezcla con otro estructuralismo, de tipo economicista proveniente de la influyente formulación cepalina, le prodiga una aplastante atención a las estructuras, sobre todo a las relaciones económicas, principalmente externas, relegando a la oscuridad la peculiar complejidad de la dinámica política latinoamericana, y con ello la de sus relaciones internas de poder.

Coopera facilitando el arraigo de estas concepciones una pesada influencia positivista sobre el pensamiento latinoamericano, y en particular sobre la forma en que se ha asimilado el marxismo en la región. Durante el siglo XX se impone en el movimiento comunista, de la 
mano de las exigencias instrumentales de su política, un socialismo científico sesgadamente positivista, que lleva a ignorar la especificidad de los sujetos populares en América Latina y con ello a abstenerse de toda tentativa de historización crítica de los procesos sociales latinoamericanos (por ejemplo, de procesos tan relevantes como la revolución mexicana). Es una tradición anterior a la llegada de Althusser por estos lares, anclada ya en la actividad intelectual de los años sesenta, influencia que estimula la búsqueda de falsos atajos intelectuales al propugnar la adopción de discursos teóricos que, gracias a su aparente rigurosidad conceptual, devuelvan a la izquierda la oportunidad de refundar su condición de portadora de una verdad cientifica, y por tanto política, después de que fuera erosionada por la crisis del estalinismo. Falsos atajos que, en definitiva, soslayan la necesidad de hurgar en la especificidad y la cultura de los actores sociales latinoamericanos.

Esa supuesta ciencia con la que terminó identificándose tautológicamente la cultura política de gran parte de la izquierda criolla, impidió advertir entonces -y aun hoy- la relevancia de los componentes historicistas, claramente no predominantes, que integraban la llamada teoría de la dependencia. De tal suerte, no ha de extrañar que vertientes historicistas dentro del marxismo, como la impronta gramsciana, no alcanzaran mayor arraigo en América Latina. Pese a que Mariátegui ya presentaba a Gramsci y su Ordine Nuovo allá por 1921, no tendrá mayor continuidad. Se trata una vertiente marxista enfrentada tanto a la influencia positivista, a la que Gramsci consideraba una nuova teologia materialistica basada en una noción de ciencia asumida como una superiore stregoneria (brujería superior), así como enfrentada también al economicismo vulgar. Pero son precisamente estas variantes las que encuentran un terreno propicio para desarrollarse, bajo la forma de un economicismo estructuralista marcadamente determinista, en un escenario latinoamericano en donde, desde su llegada y a partir del clima cultural predominante desde el siglo XIX, el marxismo se leyó bajo una pesada clave positivista. Así pues, en su opción estructuralista, el marxismo de la teoría de la dependencia obvia a un Marx que, en la práctica, llevó su reflexión a descender hasta el difícil problema de la dialéctica de lo concreto.

\section{Una conciencia de la conciencia}

Pese a ello, la teoría de la dependencia, aunque frustrada en términos de construir una historización crítica de los procesos sociales latinoamericanos, constituye empero el punto más alto alcanzado por una tendencia intelectual orientada a la búsqueda de un anclaje político. No obstante, sigue insatisfecha la necesidad de una historización de la política por parte de las fuerzas subalternas del continente. Como se ha dicho, es muy probable que a ello hubiese remitido una influencia más gramsciana que althusseriana ${ }^{45}$, en tanto puede ser considerada como inspiradora de una tentativa de latinoamericanizar América Latina.

Aun está pendiente, respecto del pensamiento latinoamericano, una crítica histórica de su construcción, una revisión que remita -en términos de Lukács- a una teoría de la teoría, a una conciencia de la conciencia. Ello implica asumir ciencia y conciencia como productos históricos. Al analizar el desarrollo de la reflexión criolla, sus etapas de clarificación o confusión intelectual, hay que recuperarla desde el proceso histórico del cual resultan tales

\footnotetext{
${ }^{45}$ Massardo, Jaime, Investigaciones sobre la historia del marxismo en América Latina, Bravo y Allende Editores, Santiago, 2001.
} 
modos de plantear los dilemas y sus soluciones. El auge que registra desde los postulados cepalinos hasta la llamada teoría de la dependencia ocurre en un tiempo en el que, en casi toda América Latina, se avivan expectativas de cambios económicos y de democratización social y política, pero en donde a su vez esas expectativas no se cumplen, tanto por la efectiva resistencia de los grupos de poder como porque quienes ascendían a los gobiernos, encarnando tales expectativas, no logran resolverlas en medio de la aguda pugna social. El tema de la dependencia surge así en medio de una experiencia política extraordinariamente compleja, plagada de conflictos y frustraciones, al tiempo que de expectativas y esperanzas.

En términos ideológicos los años sesenta son de gran dinamismo. Especialmente ilustrativo para tiempos como el actual, es el hecho que ello alcanzara a la propia iglesia católica. Su renovación hacia una orientación progresista llegaba a cobijar en su seno a grupos cuyas inquietudes no distaban mucho de la vieja izquierda e incluso de los nuevos movimientos revolucionarios. Uno de los cambios más relevantes es la crisis del viejo progresismo, donde entre los jóvenes, y en no pocos intelectuales, arrinconando al viejo valor de la moderación campea entonces el ideal de rebeldía. $\mathrm{Y}$ acaso tan ilustrativas como las ideologías políticas son algunas manifestaciones culturales para el contexto en que se sitúa el tema de la dependencia. Como se sabe, en la literatura, por ejemplo, son los años del boom latinoamericano con García Márquez, Vargas Llosa, Fuentes, Cortázar y tantos otros donde, una nueva novela que conserva la preocupación social precedente pero que incorpora una mayor inquietud por el individuo, resulta expresiva de una nueva forma de conciencia cuyo tema común es la comprensión de la realidad latinoamericana.

Le tocó a Chile entonces ser sede de instituciones abocadas al desarrollo del pensamiento latinoamericano, que reúnen a muchos intelectuales y devienen en espacio de intercambio tanto del pensamiento como de experiencias políticas. El clima político social chileno influye así en algunos rasgos que adquiere el debate sobre la dependencia. Cuestiones como las formas, el carácter y los límites de los procesos de cambio o bien el papel de las clases y grupos sociales, aparecen como posibilidades no sólo teóricas sino como opciones prácticas reales. Es, en general, un clima de confrontación no sólo político sino también intelectual, en el que las simplificaciones ideológicas son una característica arraigada.

Y es que la polarización del conflicto social ha alcanzado ya un punto sin retorno. Si en el momento del surgimiento de las llamadas alianzas desarrollistas la oposición entre lo moderno y lo tradicional parecía ser la dicotomía básica que la distinguía del resto de las opciones sociales, a poco andar ya cobran relevancia los conflictos dentro de la alianza modernizadora. En muchos casos es la reforma agraria -como afectación del sector que entonces representa lo atrasado y tradicional- la que trae el quiebre de dichas alianzas. Además, si el desarrollismo de los años cincuenta y sesenta llevó la marca de un cierto nacionalismo, a fines de esa etapa ya se abre un movimiento de inversiones extranjeras hacia la región que reverdece la asociación entre empresarios extranjeros y nacionales.

Ahora bien, lo que se agrupa como teoría de la dependencia, aunque profundiza la lectura del subdesarrollo latinoamericano, no tiene la unidad del pensamiento cepalino, por lo que se cuestiona su calidad de teoría. No obstante, se coincide que en su génesis confluyen la crisis del desarrollismo y la crítica creciente dentro de las izquierdas criollas de las tesis de la III Internacional estalinista que caracterizaban a América Latina como una situación de 
economía colonial, lo que definía el conflicto como anticolonial y sustenta la tesis de la revolución democrático-burguesa, antifeudal y antimperialista. Desde diversas vertientes, jóvenes intelectuales en los años sesenta discrepan tanto de la vieja izquierda, como del desarrollismo y de la CEPAL. Afirman la existencia del capitalismo en América Latina y lo imposible de una alianza con una burguesía nacional independiente, por ilusoria.

La teoría de la dependencia parte de la CEPAL, pero niega que desarrollo y subdesarrollo sean un continuum. Coincide en definirlas como realidades estructuralmente unidas y contrapuestas, una como la contracara de la otra y el subdesarrollo aparece ya no como una etapa hacia el desarrollo, sino como una expresión del desarrollo capitalista mundial. Esa es la tesis básica, que niega la idea del desarrollo capitalista autónomo: el desarrollo capitalista crea un tipo de capitalismo que no puede nunca ser igual al capitalismo desarrollado. El subdesarrollo resulta, pues, inherente al capitalismo dependiente. De allí la fórmula que Gunder Frank popularizara como desarrollo del subdesarrollo: cuanto más se desarrolla el capitalismo dependiente, más subdesarrollado es, más agudas son sus deformaciones. Lo que no implica necesariamente estancamiento, sino que la dependencia no se supera en los marcos del capitalismo y más bien se agudiza, por lo que no son solucionables los problemas sociales de América Latina dentro de dichos marcos.

Los dependentistas sostienen que las alternativas económicas con que se intenta resolver el problema del atraso no son neutrales y que, al contrario, tienen un claro sentido político. En definitiva, que el problema del desarrollo es un problema de poder. Empero si las diferencias en la caracterización del poder imperante parecen menores, éstas resultan insalvables cuando se trata de definir el carácter del poder posible y aquí, a menudo, la pugna es entre los dependentistas. Para muchos ello implica ligar la lucha antimperialista y anticapitalista, la lucha contra la dependencia y por el socialismo. La economía dependiente aparece como un producto del desarrollo del capitalismo mundial y del imperialismo; lo que lleva, entre otras cosas, a reenfocar el análisis del Estado, visto ahora como Estado dependiente. Se sostiene que la dependencia no debe verse principalmente a través de las relaciones mercantiles, como hacía la CEPAL, sino ampliarse a otros planos en el marco de las relaciones con el imperialismo, tomando el conjunto de fenómenos latinoamericanos -o sea la cuestión cultural, social, política- en relación con el desarrollo del capitalismo mundial. Pero la opción socialista produce diferenciaciones entre los dependentistas.

Un enfoque distinto es el de F. H. Cardoso y Enzo Faletto ${ }^{46}$, que plantea la superación del determinismo de la concepción estructuralista articulando los ámbitos social, económico y político en un análisis integrado, que recupere la relación dialéctica entre estructura y proceso histórico, lo que remite a asumir el fenómeno en sus condiciones concretas, tanto estructurales como a patir de factores como el rol de los movimientos sociales o los sistemas de dominación, en sus relaciones y determinaciones mutuas. Ello replantea la relación entre lo externo y lo interno en la formación histórica de las sociedades latinoamericanas, cuestionando la determinación externa del esquema estructuralista. Para Faletto y Cardoso si bien los países latinoamericanos ocupan una posición subordinada en la economía mundial, de modo que las decisiones internas referidas a las modalidades de

${ }^{46}$ Cardoso, F. H. y Faletto, E, Dependencia y desarrollo en América Latina. Ensayo de interpretación sociológica, Ed. Siglo XXI, 13a. ed, México D.F, 1977. 
producción y de consumo local son tomadas en función de la dinámica de las economías centrales, eso se completa con el hecho de que los grupos y clases sociales locales no resultan pasivos en la definición de esos lazos de dependencia, al contrario, actúan constituyendo internamente las condiciones económicas y políticas que posibilitan una forma específica de vinculación externa, en función de sus propios intereses. Así, detentar el poder político interno resulta clave para incidir en la forma concreta que la dependencia asume; mientras, otros grupos y clases sociales pugnan por redefinir la relación de dependencia imperante, tratando unos de superarla, otros de alterarla a su favor. De tal modo, en torno a las formas de constitución de la dependencia -su estabilidad, reajuste o superación- ocurren muchos de los conflictos sociales más importantes en los países latinoamericanos, y en cada uno de ellos el proceso asume un rasgo que lo diferencia de los demás. Luego, si para la CEPAL la industrialización periférica es espontánea al ser efecto de los cambios en el sistema centro-periferia al cambiar el centro cíclico, aquí se trata más bien de un cambio de la situación de dependencia en un proceso histórico en el que inciden las condiciones políticas y sociales internas, donde junto al auge de los grupos exportadores crecen los sectores urbanos, y un nuevo equilibrio de fuerzas internas asume la relación con Estados Unidos y posibilita y le da forma a una industrialización que no sigue un curso tan mecánico, ni aun en los países que más se industrializan. A fin de cuentas, ello remite a la dimensión política, a cómo los grupos dominantes se articulan para imponer su control y organizar el proceso productivo. Los distintos cursos nacionales se deben así a la forma como las clases y grupos sociales, tradicionales o nuevos, desarrollan su fuerza (a través de partidos, del Estado, alianzas políticas y organizaciones sociales) para imponer un orden de dominación viable.

Otros enfoques -como el de Bambirra ${ }^{47}$ - encaran frontalmente a la CEPAL como ideólogos burgueses o la ciencia oficial, constituyéndose en una extrapolación simplista de las influencias antes anotadas. La aplicación de los conceptos de Marx encontrará expresión en el trabajo de Marini, al rediscutir las nociones de productividad, plusvalía relativa y superexplotación sobre la realidad regional ${ }^{48}$. Se apreciará el subdesarrollo desde la perspectiva de la acumulación de capitales a escala internacional, como hacen Sunkel y $\mathrm{Paz}^{49}$, o bien asumir el enfoque de la dependencia como un complemento de la teoría del imperialismo, como hace Dos Santos ${ }^{50}$, mientras otros autores, como Nun y Quijano ${ }^{51}$, vinculan los problemas de la marginalidad y la dependencia.

Al situar la cuestión de la dependencia como un problema casi exclusivamente económico, como una economía externa que condiciona a una interna, la lectura predominante se

\footnotetext{
${ }^{47}$ Bambirra, Vania, Capitalismo dependiente latinoamericano, Ed. Siglo XXI, México D.F, 1979, y Teoría de la dependencia: una anticrítica, Ed. Era, 2a. ed, México D.F, 1983.

${ }^{48}$ Marini, Ruy Mauro, Dialéctica de la dependencia, Ed. Era, 2a. ed, México D.F, 1974.

${ }^{49}$ Sunkel, O. y Paz, P, El subdesarrollo latinoamericano y la teoría del desarrollo, Ed. Siglo XXI, México D.F, 1970.

${ }^{50}$ Dos Santos, Theotonio, Imperialismo y dependencia, Ed. Era, 4a. ed, México D.F, 1986.

51 Nun, José, Superpoblación relativa, ejército industrial de reserva y masa marginal, Revista Latinoamericana de Sociología, Vol. 5, No. 2, Santiago de Chile, julio, 1969, y Quijano, Aníbal, Redefinición de la dependencia y proceso de marginalización social, en Weffort, F. y Quijano, A, Populismo, marginalización y dependencia. Ensayos de interpretación sociológica, Universidad Centroamericana, San José, 1973.
} 
desentiende de la variedad y complejidad de construcciones que arroja el proceso político y social latinoamericano. El atraso de América Latina, y buena parte de la fisonomía de sus sociedades, aparecen como efecto de tal subordinación económica. De ella emanan, en tal visión, condicionamientos determinantes sobre sus sistemas políticos y socioculturales. Gran parte del conocimiento sobre América Latina se moldea así bajo tal premisa, ubicándose allí la médula de su especificidad.

El debate sobre la dependencia se entronca con un viejo tema, casi obligado en América Latina para todos aquellos que en distintos ámbitos ejercen una función intelectual, esto es, el problema nacional y la difícil relación con el sistema internacional; sin embargo, lo hace sin prestar suficiente atención al hecho de que el modo en que ambos se articulan no es ajeno a las formas en que se constituye el poder interno. La menor atención sobre las relaciones de poder internas en esta perspectiva de análisis de la realidad latinoamericana en la que prima el interés por las estructuras, especialmente económicas, vistas muchas veces como reflejo de las determinaciones externas, lleva a que, cuando más, esas relaciones de poder internas se aprecien reducidas a la superestructura de la sociedad, vistas además como mero reflejo de las relaciones económicas, lo que desatiende las relaciones de poder presentes en la base de la sociedad y su especificidad, los modos del poder social y su peso en la configuración de la fisonomía de la sociedad. En la mirada predominante el análisis del poder alcanza, cuando más, las esferas institucionales. De ahí proviene, entre otras limitaciones, esa reificación del poder del Estado en detrimento de la situación general del poder en la sociedad, distinción fundamental en la comprensión de la realidad latinoamericana.

Particularmente en el caso latinoamericano, la visión centrada en las instituciones y el ámbito formal de la política no da cuenta de la situación general del poder en la sociedad. Subvalorar las formas extrainstitucionales del poder y su histórico peso en la base de la sociedad lleva a desconocer la constante disparidad, reiterada hasta nuestros días, entre la institucionalidad y la política formal, por una parte, y las formas de regulación de las relaciones sociales a nivel de la base de la sociedad, por otra. La consideración -además de las formas del poder político formal- de los diversos y culturalmente arraigados modos del poder social, es fundamental para entender la realidad latinoamericana, no sólo pretérita, también contemporánea, incluidos sus procesos políticos, pues ello cobra un peso decisivo, a ratos incluso mayor que las instituciones formales propiamente tales, en la formación de la cultura. Superar esta cuestión exige una visión más amplia de las estructuras de poder, del ejercicio del poder como tal, que supere -aunque la integre- la percepción reducida al poder del Estado. Es reiteradamente claro en América Latina el hecho que el poder social de sus grupos dominantes trasciende al Estado (lo que no quiere decir que prescinda de él), que muestra una desconcertante capacidad de consolidarse más allá de éste. Por lo que la mirada sobre el poder político debe incorporar las formas extraestatales de poder, dada su decisiva capacidad de proveer estabilidad sistémica y obstaculizar los cambios sociales.

Pese a todo lo encomiable del esfuerzo reseñado por pensar la región, la extrapolación de sus conclusiones hasta una imposible sobreexplicación de toda la realidad, acabó arrojando una pesada oscuridad sobre la naturaleza específica del poder y la dominación en América Latina. Ello se tradujo en una visión simplista de la constitución y las posibilidades de acción de los sectores populares, reducida a un despertar de la conciencia que, en tal lógica, 
equivalía a la aprehensión de ciertas predicciones estructurales. Con eso el problema del cambio social en América Latina se perdía la posibilidad de un esfuerzo de indagación que entrara al fondo de sus condiciones histórico-concretas.

Es que, aunque de necesaria consideración, el patrón europeo de ideologías políticas no guarda un calce suficientemente ajustado con la situación latinoamericana contemporánea. El balance del recién extinto siglo XX es tajante al respecto: ello explica buena parte del fracaso de las formaciones políticas de semejante inspiración, y el éxito relativo de movimientos de arraigo popular arropados con una confusa mezcla de nacionalismo, reformismo social y autoritarismo. Más que claras ideologías de clase, como las que se han distinguido al alero del desarrollo del capitalismo en Europa, una impronta más aferrada a una ideología nacional-popular es lo que parece haber primado en los procesos sociales y políticos más importantes del siglo XX latinoamericano. El hecho de que el destino de los regímenes posdictatoriales que hoy estamos viendo, de las esperanzadoras -en su rato casi en un sentido civilizatorio sarmientino- democracias recientes, sea pues en gran parte de los países latinoamericanos bastante más pobre y conservador de lo esperado, además de incierto, es otra más de las muestras que la historia de América Latina arroja de ello.

No es el caso aquí revolver las cenizas de viejas reyertas. Lo que importa es que, entre los costos de aquella simplificación en la mirada sobre América Latina se cuenta el que, junto al derrumbe de esas modas parisinas, y luego del colapso de otros aun más rígidos dogmas moscovitas, se desplomara también la discusión latinoamericana, en especial sobre la peculiaridad no sólo económica y cultural, sino política y social de América Latina, y con ello de sus posibilidades. Sobreviene un sesgo antidependentista que, aparte de cuestionar con razón muchas exageraciones, prosigue desdibujando el peso de la innegable condición de dependencia, echando con eso más sombra sobre los problemas y la especificidad de la región. Caricaturizada y luego olvidada, aquella prolífica discusión prácticamente va a desaparecer. Después del pensamiento cepalino y la teoría de la dependencia no surgirán temáticas que ocupen en forma sostenida el centro de la elaboración sobre América Latina.

En la segunda mitad de los años setenta prima el cuestionamiento y el abandono de los postulados dependentistas. Cueva expresará la reactivación de la crítica de la izquierda tradicional a dichas formulaciones por su excesivo énfasis en las relaciones entre naciones, en tanto oscurecen las relaciones entre las clases sociales ${ }^{52}$. Pero es sobre todo la crisis de la izquierda latinoamericana lo que incide en el ocaso de la preocupación por la dependencia y su sustitución por otros temas más efímeros. Al inicio se trata de la caracterización de la nueva oleada de autoritarismo en América Latina, luego de los nuevos movimientos populares, muy ligado esto último al declive del análisis en términos de clase sociales y, posteriormente, de la llamada modernización del Estado, vinculada a la adaptación del Estado latinoamericano a las nuevas modalidades neoliberales de desarrollo capitalista.

Más que el problema del desarrollo y su inevitable concomitancia con las raíces del atraso, ahora parece primar, algo redibujado, el tema de la democracia, en unas naciones cruzadas por el agotamiento tanto de la dominación militar como de las viejas formas democráticas.

\footnotetext{
${ }^{52}$ Cueva, Agustín, Teoría social y procesos políticos en América Latina, Ed. Edicol, México D.F, 1979.
} Recopilación de artículos donde puede verse El desarrollo de nuestras ciencias sociales en el último período. 
La emergencia de una demanda democrática en América Latina motiva un análisis que, sin embargo, acaba a menudo reducido a los problemas de la gobernabilidad, la capacidad normativa del Estado o los déficit sistémicos de integración social. Pero, además, es innegable que en este cambio de orientación de la reflexión criolla incide la inquietud por variados fenómenos políticos, sociales y culturales cuya explicación no la agota el registro de los condicionamientos emanados de la posición subordinada de nuestras economías en el concierto mundial. De tal modo, el declive de la atención sobre el tema de la dependencia se explica, en parte, en razón de que la realidad latinoamericana impone otras urgencias. Muchos países viven dictaduras militares o sienten aproximarse el autoritarismo. El análisis de tal fenómeno y su diferencia con regímenes militares anteriores acapara la atención. La búsqueda de una salida a ello, y la propia experiencia de recuperación de ciertas formas institucionales democráticas, ubica en el centro de la reflexión el tema de la democracia.

Pero eso no es todo. Si la realidad impone otras urgencias, donde el tema de la dependencia pierde prioridad, también se arguyen otras razones, más dudosas, para restarle importancia. Se plantea que la situación mundial ha cambiado, y con ella el contexto local, que prima ahora un proceso de globalización cuya expresión más clara es la internacionalización de la economía y que además tiene correlatos políticos y culturales, como el desplome del bloque socialista, lo que termina con la vieja importancia política de los países del tercer mundo. A esto se sumaría el fenómeno de la revolución científico-técnica que, mostrado a menudo como inédito y determinante, alteraría el basamento de las viejas opciones de desarrollo socioeconómico. La idea de una nueva modernización que avanza redibujando la situación mundial a través de la globalización, hace pensar a muchos que el tema de la dependencia y sus correlatos de soberanía nacional carecen ya de importancia, siendo superados por la nueva realidad. El imperativo de la urgente integración a la nueva modernidad relega así el análisis de las nuevas modalidades de dependencia -fenómeno que no desaparece, todo lo contrario- en la nueva etapa histórica. No obstante, si las posibilidades democráticas y los dilemas que trae la globalización priman hoy en la reflexión sobre América Latina, se carece de líneas de indagación claras y articuladoras. Trátase de una diversidad que parece evitar toda perspectiva integradora. La resignación a lo descriptivo, el auge de teorías parciales, de alcance medio y el encierro en los microprocesos, se cruza con el mismísimo entierro de las ciencias sociales, del método o de la certidumbre. ${ }^{53}$

El consabido ánimo agnóstico, emanado del sueño utópico del vencedor por conservarlo todo como está en el orden natural de su momento predilecto -versión criolla del fin de la historia- ensombreció la reflexión sobre la realidad latinoamericana, orillando al margen a toda renuencia sobreviviente. Tras la moda althusseriana, una vez que las estructuras fueron liberadas de todo sujeto y entregadas a su propio juego, acaban después, con la caída del estructuralismo -de la mano de Foucault, Derrida, Deleuze- en un postestructuralismo hijo de la desmoralización que sigue a la derrota de la revuelta del 68, aboliendo lo que las definía como estructuras, o sea, sus ejes objetivos de organización, privando nuevamente de sentido la acción del hombre, esta vez a manos ya no de la vieja causalidad estructural sino del imperio de la absoluta casualidad. En fin, una subasta subjetivista que pasa de la

\footnotetext{
${ }^{53}$ Véase, por ejemplo, Brunner, J.J, Sobre el crepúsculo de la sociología y el comienzo de otras narraciones, Revista de Crítica Cultural, No. 15, noviembre, Santiago de Chile, 1997; o el uso de las tesis de Feyerabend o de Ilya Prigogine.
} 
momificante imagen de las estructuras objetivas prácticamente independientes del juego de los sujetos, a un subjetivismo sin sujeto. Siempre influyentes tales modas sobre la reflexión criolla, la tarea de la historización de las problemáticas locales volverá a quedar relegada.

\section{El cambio de la perspectiva intelectual con la transformación reciente}

Todo este giro no responde a un capricho intelectual. Es parte de la historia inmediata de la región que, entre otras cosas, arroja una redefinición del rol de los propios intelectuales. Como se ha dicho, luego del debate de la dependencia avanza gradualmente, hasta primar, una tendencia a que la intelectualidad criolla hable de unas sociedades latinoamericanas inexistentes, analizadas y pensadas para los europeos o los norteamericanos ${ }^{54}$. Así, se habla poco de América Latina con los latinoamericanos, marcando una dilatada tendencia que se traduce en una falta de pensamiento propio, sequía de la reflexión que va unida a una metamorfosis de la política. Pues lo que se desvanece, en definitiva, es un pensamiento que se desarrolló muy ligado a los procesos sociales y a una idea de la política como proceso social. Como se señaló, uno de los primeros hitos de este giro está en la discusión sobre los nuevos movimientos sociales, tema que se asume como liquidación y superación tanto de las clases sociales como de los partidos, lo que va unido a la ruptura con los partidos de la izquierda tradicional. Lo trascendente de esto es que se produce en un momento en que los llamados procesos de transición o redemocratización enfrentan el dilema de la reforma político-institucional, es decir, están dirimiendo la concepción de la política que primará en adelante. Ahí empieza el predominio incontrarrestado tanto de la tecnocracia económica como de una reflexión política reducida a una suerte de ingeniería política. No es ajeno a ello, entonces, que los desvelos de la democratización se reduzcan a la recuperación parcial de la institucionalidad formal y no se asuma el imperativo de una democratización social.

El giro en la reflexión económica es ilustrativo. Si los intelectuales de los años cincuenta en adelante se forman en el predominio de la economía política, y en la idea de ligar la política al proceso social, ya desde fines de los años setenta la discusión económica se ocupa más del manejo del presupuesto fiscal o la deuda externa que de propuestas de transformación social. Por todo cambio, se asume que éste llega desde afuera con la globalización, cuya modernización acarreada -se supone- trae un bienestar socialmente extendido. Es un curso donde la reflexión pasa del análisis de la dinámica social y económica asumida como procesos de conflictos y cambios entre clases y grupos, a una mirada centrada en las formas institucionales de administración política y económica, lo que se acompaña de una reorientación de la formación universitaria bajo una óptica profesionalizante y tecnocrática.

Es un giro intelectual que va unido a los cambios sociales que ocurren en este tiempo. El predominio de la orientación tecnocrática obedece al enmudecimiento y la desarticulación de algunos grupos sociales muy relevantes en la historia de América Latina desde los años veinte en adelante, que constituían los referentes sociales de buena parte del pensamiento latinoamericano. Se trata de los sectores medios, obreros y luego campesinos. Pero desde los años setenta -en Brasil, de la década anterior- con los golpes militares y la reacción que sigue en la mayor parte de América Latina, lo que avanza es la desarticulación de aquellas

\footnotetext{
${ }^{54}$ Entrevista a E. Faletto, Enzo Faletto rompe tres décadas de silencio: Necesitamos una nueva ética del comportamiento, Revista Rocinante, Arte, Cultura y Sociedad, Año V, No.41, Santiago, marzo, 2002.
} 
clases medias y del movimiento obrero y campesino. Los grupos intelectuales quedan sin sus viejos referentes sociales, lo que estimula su figuración como una entelequia situada por encima de los diversos intereses sociales, portadora de una racionalidad impermeable a los conflictos sociales. A fin de cuentas, carentes de referentes sociales concretos e inmediatos, estos grupos intelectuales se ligan a las diversas esferas del poder imperante, reinstalando de cierto modo la vieja figura del intelectual cortesano. Se impone así una tecnocracia cuyo brillo intelectual radica en su eficiencia y cuyo mundo de referencia -a diferencia de la vieja intelectualidad- es el poder existente. Sus opciones se reducen al uso de sus capacidades tecnocráticas para influir en el poder constituido, sin posibilidad de cuestionar la existencia de ese poder, lo que anula la idea de transformación.

Este giro está muy ligado, además, a la metamorfosis de la política latinoamericana en las últimas décadas. De una ciudadanía de organizaciones se pasa a una de individuos atomizados, inorgánicos, lo que hace que la política pase de la tradicional arena de disputa de proyectos nacionales a redibujarse como un espacio de administración, elitizado como tal, delineándola así como una gestión de entendidos, donde la esencia de lo democrático se reduce a lo formal y su aspiración representativa a una condición meramente delegativa. Es una redefinición de la política amparada en la desarticulación de los viejos sujetos sociales.

De tal suerte, no resulta ocioso retornar a los dilemas del debate latinoamericano de hace tres o cuatro décadas, sin eludir sus limitaciones. Aquella lectura no debe ignorarse hoy, en tanto relevó una dimensión esencial de la condición latinoamericana; ni tampoco exagerar su capacidad explicativa. Aparte de enfatizar la expoliación que sufren nuestras naciones a manos de las potencias de turno y aclarar cómo nos expropian la posibilidad del desarrollo, es preciso descifrar la compleja interacción de distintos poderes, que arrojan peculiares modos de dominio y de formación cultural. La multiplicidad de fenómenos que conforman nuestra realidad no condena al pensamiento al examen de microrealidades o a reducirse a la mera administración de lo existente, remite más bien a un análisis integrador capaz de superar reificaciones y determinismos que simplifican la lectura de la condición latinoamericana. La incidencia de externalidades en su estructuración económica cuenta sin duda, pero no explica todo. El problema de la democracia tiene que ver con los rasgos que asume el poder en América Latina, con los elementos que lo especifican, lo que es inteligible sólo a partir de un análisis histórico de su conformación concreta.

Es preciso superar esa recuperación de la historia centrada en develar el atraso de América Latina, que intenta explicar su configuración contemporánea como un puro efecto de su eterna posición subordinada en las relaciones económicas internacionales. Sin ignorar este elemento -como se ha puesto de moda, llegándose así al otro extremo- es preciso superar la exageración de su capacidad explicativa respecto de nuestra especificidad. Lo que obliga, en tal sentido, a situar la relación entre economía y política a partir del desarrollo histórico. Hay que recuperar y resituar esas temáticas elaboradas entre los años cincuenta y setenta del siglo pasado y luego abandonadas bajo modas que poco ayudaron a entender la peculiar lógica de los procesos políticos y sociales latinoamericanos. El peso del conflicto político sobre aquella discusión llegó a ser practicamente determinante, lo que no debería extrañar si no fuera porque acabó imprimiéndole formas contradictorias. De la reflexión inicial, forjada en círculos intelectuales académicos y otros ligados a organismos internacionales y agencias estatales abocadas a la reforma y la planificación, se pasó a la masificación del 
debate conforme proseguía la polarización social y política. Como se sabe, la discusión adquiere gran visibilidad y tras sus planteos se agolpan intransigentes barras de seguidores, con lo cual la controversia adopta un cariz sobreideologizado que impide ahondar en las problemáticas que la originaron. Pese a que arroja novedades, gran parte de la elaboración se aboca a apuntalar los distintos postulados políticos en torno al dilema de la inminencia del cambio social. En definitiva, en una forma poco asimilable a la supuestamente inspiradora tradición clásica del marxismo, que cobija una labor intelectual en función directa de la lucha política y sus problemas organizativos, en el caso de latinoamericano, contrario a las apariencias, en esta etapa se trata más bien del divorcio de esas dimensiones. Similar a lo que ocurre con la irrupción althusseriana, cuya vehemencia sólo nubla la ausencia de un genuino pensamiento estratégico, en el caso latinoamericano, pese a la drasticidad del discurso, figuras emblemáticas de este proceso como A. Gunder Frank o Vania Bambirra son académicos que se vinculan sólo en cuanto tales al proceso político, por lo que, a pesar de afanarse en dar un sustento teórico a ciertas tesis políticas, no son estrategas ni constructores políticos como tales. Pero lo que deja el curso que revierte aquél proceso político, es el enmudecimiento del pensamiento latinoamericano o, si se prefiere, su dispersión en temáticas parciales por derroteros que llegan a un franco agnosticismo ante la posibilidad de comprender los problemas que estaban en el origen de aquella reflexión.

En su celebrada Historia del siglo $X X$, haciendo un balance del siglo pasado Hobsbawm ofrece la imagen de un sombrío fin de milenio, afectado por una crisis de alternativas ${ }^{55}$. No es sólo la hondura y complejidad de la crisis mundial sino, además, un aparente fracaso de todos los programas, nuevos y viejos, para manejar o mejorar los asuntos de la especie humana. Por encima de otros rasgos, señala, fue un siglo XX cruzado por el derrumbe de la civilización occidental que madura en el siglo XIX. Un siglo XX lleno de fracasados intentos por evitar el derrumbe de la cultura occidental burguesa. Si ello es así aunque sea en alguna medida, más que leer el presente latinoamericano a partir de modas foráneas, es preciso hurgar en nuestra especificidad para discernir lo que somos y lo que podemos ser, lo que implica, entre otras cosas, reconstruir el diálogo intelectual latinoamericano. La mentada crisis de la modernidad, de la racionalidad occidental y sus correlatos de posmodernidad, no son vectores a trasladar mecánicamente de Europa y Norteamérica a la América Latina de los inicios del siglo XXI. La modernidad asumió aquí una forma peculiar, así como el propio capitalismo y la conformación de la cultura política. La realidad latinoamericana se construye sin duda bajo la matriz de la cultura occidental, pero no se reduce a ella. Más bien la adapta. Las influencias externas se procesan históricamente en el complejo metabolismo criollo, arrojando importantes peculiaridades. Eso especifica las construcciones resultantes originando un dilema con los corpus teóricos predominantes, forjados para comprender una realidad moldeada por un curso histórico diferente.

La atención a la especificidad de la condición latinoamericana no significa reducirse a un singularismo folklórico esmerado en distanciarnos forzadamente de Occidente. Más bien busca completar desde nuestra propia realidad un pensamiento universal, en una forma que no puede hacerlo la lectura eurocentrista sino que sólo lo pueden hacer las lecturas inscritas en mundos cuyas peculiaridades han sido ignoradas por esa orientación dominante. En tal sentido, el registro de la especificidad latinoamericana ha de ser un aporte insustituible a la

\footnotetext{
${ }^{55}$ Hobsbawm, Eric, La era de los extremos. El corto siglo XX (1914-1991), Ed. Crítica, Barcelona, 1995.
} 
forja de una concepción plenamente universal acerca de la sociedad y la historia humana, a una visión de su desarrollo que no confunda occidental con universal, elaborando a partir de su peculiaridad dilemas que deben ensanchar la edificación de la teoría, superando los límites de la experiencia puramente occidental. Plantear así la experiencia latinoamericana como la cara colonial de la modernidad, como una diferenciada modernidad periférica y no como un curso eternamente a la zaga de la modernidad occidental, vista a menudo como ideal. Si ambos procesos, allende y aquende el Atlántico, se asumen como partes del mismo curso histórico, estrechamente ligados entre sí, aunque no en forma determinista, esta perspectiva representa no sólo la posibilidad de un mayor conocimiento particular de cada experiencia histórica sino de un aporte a la teoría como tal. La visión eurocentrista conlleva una estrechez cuya superación no significa negarla sino ampliarla con nuevos dilemas, tensionando sus moldes en vez de aplicarlos rígidamente a la realidad latinoamericana. Así, nuestra singularidad debe asumirse como una parte irreductible de lo universal. Ni el poco novedoso posmodernismo ni el viejo determinismo son de gran ayuda en esta tarea, en tanto uno como otro evaden la historización del conocimiento sobre América Latina.

\section{Historizar la lectura del presente}

Se requieren otras vías para descifrar el ciclo político abierto en las postrimerías del siglo $\mathrm{XX}$ en América Latina. Una de ellas es la que pone la atención principal en la naturaleza del poder y las clases y grupos que lo encarnan. Esto exige considerar su especificidad, lo que remite a recuperar los procesos de formación histórica del poder en América Latina, para revisar la caracterización de los procesos políticos y las sociedades latinoamericanas. Replantear así la mirada sobre los procesos políticos actuales en América Latina a través de una relectura de la formación histórica del poder, recuperando su especificidad, lleva a situar de un modo distinto al habitual -plagado de modelos ideales foráneos- problemáticas como la de las posibilidades democráticas, del crecimiento con equidad o la del cambio social. Significa partir de sus condiciones histórico-concretas y no de paradigmas políticos e ideales normativos surgidos del curso histórico europeo y norteamericano, cuya utilidad reside, más bien, en el diálogo que permiten con dicha historia. Esto debiera permitir un acercamiento fructífero a cuestiones como las formas históricas de la democracia, y en particular a los tipos o formas de ésta que se corresponden a la realidad latinoamericana, a los problemas específicos de su construcción. En tanto examen de la formación histórica del poder en América Latina, esto significa un examen de las condiciones históricas de realización de la democracia en la región. Perspectiva en la cual es fundamental atender y recuperar los procesos sociales no sólo en sus momentos de realización, como resulta predominante, sino en su más larga formación histórica atendiendo a la influencia que también esta produce. Tal y como si surgieran de la nada, los momentos de realización del poder, a menudo más impactantes, productores del anecdotario al que luego los simplismos reducen el relato, suelen relegar a la oscuridad sus procesos de más lenta formación. Por eso el análisis de los sistemas políticos actuales en América Latina remite, entre otras cosas, a observar cuestiones como el proceso histórico de constitución de sus estructuras de poder, de conformación de la cultura política, del Estado, los grupos de poder, las formas de dominio, sus órdenes de legitimación, a la naturaleza específica de las clases dominantes.

Los esfuerzos de indagación producen una acumulación de conocimientos en torno a ciertas particularidades de la condición latinoamericana, pero centrados principalmente en aquellas 
de tipo económico (estructurales sobre todo) o de índole cultural (mayormente folklóricas, testimoniales). En cambio, la lectura del poder y de los procesos políticos no se orienta en igual medida bajo esta óptica. Sin embargo, la lectura desde la perspectiva de los problemas de la formación histórica del poder, en tanto examen de las fuerzas y los procesos que realmente han configurado a América Latina, permite en mayor medida una visión de la totalidad y de su especificidad, no sólo política sino también económica y sociocultural, así como de los modos reales de articulación entre sus partes o factores (problema que suele discernirse en virtud de modelos teóricos como los antes aludidos). Lo que implica asumir para ello el estado general del poder en la sociedad, las formas, sujetos, estructuras y las relaciones de poder que efectivamente se establecen, y no sólo su expresión formal en instituciones. El curso de destrucción de las estructuras coactivas particulares -los poderes fácticos- por la vía de procesos de secularización, de limitación de los poderes corporativos, y como contraparte de eso, la formación del único poder coactivo legítimo en un contexto republicano, el del Estado, presenta en América Latina un devenir anómalo respecto del ideal capitalista, o burgués si se prefiere, lo que particulariza a los sistemas políticos. Este es un proceso rastreable desde la temprana etapa colonial. O el sistema de poder en América Latina no corresponde al ideal capitalista o burgués, o bien al igual que se ha postulado para la economía, en su periferia el capitalismo también produce, en cuanto a las estructuras de poder y los procesos políticos, un modo de conformación y desenvolvimiento intrínsecamente distinto, no necesariamente liderado por burguesías.

El devenir de América Latina está marcado por la acción de fuerzas cuya naturaleza no se reduce a las que registran otras realidades. Pero la originalidad que esto produce se tiende a asimilar bajo una perspectiva eurocentrista, desde la cual las peculiaridades de la condición latinoamericana aparecen como distorsiones ocurridas en las orillas misteriosas del mundo occidental. Creamos así un espejo en el que no somos lo que somos. Cómo dejar de ser lo que no somos es el dilema. La especificidad de América Latina no se agota en dicotomías como capitalismo vs. feudalismo, o entre lo moderno y lo tradicional. La acostumbrada asociación de capitalismo y modernidad no opera históricamente en América Latina en forma clara y sostenida. La expansión capitalista, en formas coloniales y neocoloniales, aquí lleva también a conservar estructuras arcaicas. Hay etapas de expansión económica, pero manteniendo el poder y las estructuras asociadas a los grupos tradicionales. Otras veces hay modernización -educativa, de consumo- sin verdadero crecimiento económico.

Si se examina desde la perspectiva de los procesos de formación de las estructuras de poder, la historia de América Latina muestra las dificultades del surgimiento de una burguesía. Lo que tiene efectos de gran importancia en la constitución de las estructuras económicas y sociales, y especialmente en la conformación de la cultura política. El siglo XIX latinoamericano muestra la afirmación de un capitalismo no liderado por burguesías. Empero, ¿qué consecuencia acarrea ello en la configuración de las clases dominantes, de los modos de dominación, de la cultura política, del sistema político, de las posibilidades de cambio social? En la primera mitad del siglo XX, en medio del auge de la industrialización criolla, en los países latinoamericanos no se puede hablar extendidamente de una burguesía autónoma respecto de un antiguo y persistente régimen oligárquico. De ahí que sea preciso situar socialmente las pugnas económicas, políticas o culturales. Sabemos que esas clases y grupos no resultan mecánicamente constituidos a partir de la estructura económica, sino que, influidos por ésta, resultan de un conflictivo curso histórico de formación en donde los 
grados de constitución o de desarticulación que experimentan van a estar relacionados y se van a reflejar en los grados de gravitación o subordinación respectivos que ocupan en las estructuras de poder. Por tanto, se trata de un problema a analizar históricamente y no sólo a partir de preceptos teóricos ni de una mecánica extrapolación de experiencias foráneas. Lo mismo vale también, por estar estrechamente ligado a lo anterior, para el análisis de las dificultades y posibilidades que existen en América Latina para la construcción de la democracia, la ciudadanía y la libertad que las burguesías han impulsado en el capitalismo desarrollado, puesto que ello remite a las posibilidades y dificultades históricas de los modos del poder, de dominio y hegemonía cultural burguesa en América Latina. Para examinar el problema de la democracia en el contexto del capitalismo hay que revisar la capacidad histórica de las burguesías que lo habitan para erigir tal régimen político, escrutar su carácter y su fuerza como clase, y en caso de no ser unas burguesías lo que prima, hay que analizar entonces los modos específicos del poder concretamente dominante. En buenas cuentas, esto plantea la necesidad de una historización del problema de la democracia y la dominación, en general de los modos de la política en América Latina, necesidad que la escolástica formalista con que ha actuado mayormente el marxismo criollo, y no menos las recientes modas posmodernas y sistémicas, han acabado por obstaculizar.

La especificidad del desarrollo histórico latinoamericano tiene que ver, entre otros aspectos, con la forma peculiar en que se relacionan política y economía, lo que significa que el poder político y el poder económico siguen una lógica propia de conformación. El desenvolvimiento político llega a adquirir un carácter predominante sobre la economía y en la conformación de la sociedad. Es un proceso que, a partir de ciertas etapas, se expresa en el papel del Estado. Inicialmente -al menos hasta entrada la segunda mitad del siglo XIXes sólo nominalmente un Estado nacional, sin control efectivo sobre la población y el territorio, sin autoridad y contenido debido a la gravitación de una miríada de poderes locales cuya autonomía patentiza la debilidad de un poder central. Eso es lo que buscarán superar liberales y conservadores para acabar con la anarquía reinante en las actividades productivas y las relaciones políticas: la creación de un verdadero Estado nacional. Es que, por su falta de desarrollo, la economía en América Latina no generó los elementos capaces de dar a los países otro proceso de unificación nacional, por lo que éste se produce a manos de un poder político capaz de imponerse, generando así una unificación política. De ahí una gran anomalía en la formación del poder político y del poder económico en la región. Es un curso más bien inverso al europeo, donde la función unificadora la cumple un mercado nacional, que se organiza al margen del Estado e incluso incide sobre este último en forma determinante. De ahí, y no por imperceptible, que en América Latina sea difícil distinguir el accionar de la mentada mano invisible del mercado, y que más bien aparezca por doquier y alcance el presente -si consideramos las privatizaciones neoliberales de fines del siglo XXuna especie de mano negra de unos poco competitivos apellidos y privilegios, a menudo decisiva en la formación y acumulación de riqueza y poder.

Pero si la formación del poder político no se asemeja a las experiencias europeas, a fin de cuentas emerge un poder político nacional. Es la lucha política, a menudo armada, la que configuró nuestros países: ni planes preestablecidos ni mecánica determinación estructural. El resultado histórico llega de los intereses que en esas pugnas maduran y se imponen. El paso de economías mercantiles a formas más complejas del desarrollo capitalista no llega sino con la unificación política de estos países. Hay una relación entre el establecimiento 
del poder nacional en América Latina y la expansión mundial del capitalismo monopolista: si tal expansión es una condicionante decisiva, no permite ignorar el papel que desempeñan las oligarquías criollas y su Estado nacional.

Con raíces en el pacto colonial, en América Latina madura bajo el proceso independentista y luego durante la anárquica ruta de formación del orden nacional oligárquico, un rasgo distintivo de las estructuras de poder, que consiste en la reiteración de pactos y equilibrios de fuerzas entre grupos con poder económico y social, que en conjunto articulan un sistema nacional de poder y dominación. Esto responde fundamentalmente a la inexistencia de una clase o grupo capaz de imponer cabalmente sus intereses al resto, lo que plantea una incapacidad para forjar un poder omnipotente en América Latina capaz de imponer una dirección económica, política y cultural coherente -como proyecto de clase- sobre toda la sociedad. De esa reiterada sumatoria de poderes de alcance parcial correspondientes a grupos sociales de diversa naturaleza, donde de haberlo, el sector dominante que encabeza la alianza no puede prescindir del resto, y por tanto tiene que dejar márgenes de realización a sus respectivos proyectos, surgen entonces los espacios para una diversidad que descoloca a menudo al analista, emanan las posibilidades para que perdure y se proyecte la acción de múltiples estrategias diferenciadoras, tanto a nivel de los grupos dominantes como subalternos, conformando una realidad necesariamente heterogénea, al punto que sea ésa, acaso, su marca más distintiva (heterogeneidad que suele apreciarse en grupos subalternos, destacándose el mosaico de sus mixturas, las yuxtaposiciones culturales, pero no así en las clases dominantes). De ahí que a la rígida mirada teoricista la historia latinoamericana se le aparezca algo así como una cuadratura del círculo, dada la coexistencia de formas históricas que en Europa resultan antitéticas, o dicho de otro modo, es debido a ello principalmente que coexisten e incluso marchan de la mano formas modernas y arcaicas, capitalistas, medioevales y hasta esclavistas, redefinidas a su vez en el contexto latinoamericano. Al estabilizarse esos pactos de poderes sociales y económicos locales, devenidos gracias a ello en poder político, proyectan sus condiciones de acumulación y se proyectan también como sujetos de negociación con los intereses externos. Y es aquí que éstos últimos, al entrar en alianza con esta miríada de grupos dominantes, refuerzan la perspectiva de un marco nacional dependiente en el que ambos realizan sus intereses respectivos.

De este rasgo de las estructuras de poder emana fundamentalmente la heterogeneidad especificante, tan característica de América Latina. Me refiero al hecho de que, aunque predomine un grupo social, es sólo en alianza con otros, sin resolver las contradicciones que puedan existir al interior de los sectores dominantes, ni constituir plenamente un proyecto coherente de transformación o modelación de la sociedad según sus intereses. De ahí también el devenir de América Latina como una historia sesgada por un latente -y a ratos irruptivo- estado de crisis que, sin embargo, no registra rupturas capaces de inaugurar un orden social más articulado y coherente desde alguna perspectiva de clase. Las contradicciones que cobija esa diversidad, sobre todo al interior de los propios grupos dominantes, no se resuelven sino que se diluyen recurrentemente en pactos de distribución de esferas de poder al interior de una ambigua estructura de dominación, lo que, en definitiva, acaba mostrando un mosaico de modos de dominación política y de control social teóricamente contradictorios a los ojos de la escolástica formalista, empero existentes y perdurables históricamente. Al final no se constituye una clase social hegemónica, capaz de pensar y reorganizar la sociedad. Más que una abúlica 
lumpenburguesía eternamente subordinada a fuerzas externas, las débiles burguesías históricas se diluyen como alternativa de transformación en alianzas con sectores tradicionales, generalmente en posiciones secundarias; inclusive, las más de las veces son precisamente los pactos de dichos grupos tradicionales con aquellas fuerzas capitalistas externas lo que relega a roles secundarios a estas débiles burguesías en el escenario latinoamericano. En tanto, un poder oligárquico, de origen colonial, muta sucesivamente a diversas formas económicas y tendencias ideológicas, desde el orden agrario hasta la peculiar industrialización criolla, en un curso de adaptaciones sin ruptura esencial, integrando diversas alianzas sociales en las cuales casi sin excepción acaba refrenando las improntas de cambio de otros sectores sociales. Precisar el límite de estas adaptaciones resulta central para entender el problema del cambio social en América Latina. Y, en esta tarea, vale aquello de que el presente siempre reinterroga a la historia, asumiéndolo como requerimiento para entender el presente y sus posibilidades. 